\title{
CONTRIBUIÇÃO PARA ESTUDO E INTERPRETAÇÃO DAS REGRAS DE JUDÔ
}

\author{
Carlos Catalano Calleja*
}

\begin{abstract}
Com o objetivo de estudar as normas dos com. bates de Judó, desde os primórdios, particulrmente após a sua transformação em esporte internacional, procurou-se analisar histórica e tecnicamente as sucessivas modificaçōes sofridas pelas regras de competição.

Constatou-se que as alteraçōes foram idealizadas no sentido de facilitar o entendimento das lutas pelo público leigo, contribuindo para a difusāo do Judó e procurando tornar os combates mais dinâmicos. com avaliaçäo das técnicas durante a luta, propiciando decisões finais, muito mais justas.
\end{abstract}

A correta interpretação das normas de competição é assunto de relevante importância, capaz de contribuir para o próprio desenvolvimento técnico de uma modalidade esportiva.

As primeiras regras da Federação Internacional de Judô foram aprovadas em 1967, no congresso Mundial celebrado em Salt Lake City, Estados Unidos.

Através dos tempos, como modalidade agonística corpo-a-corpo, devido às regras de combate, não era fácil de ser entendida pelo público leigo. Era um tanto confuso acompanhar o desenvolvimento de uma luta, considerando que os resultados parciais, com exceção do waza-ari (quase ippom ou ponto completol, não eram anunciados pelo árbitro central. Tratava-se de um assunto altamente técnico e um tanto subjetivo.
Verificou-se que as seguidas modificaçóes ocorridas principalmente nos anos setenta, contribuiram decididamente para a efetiva elevaçăo desse esporte como modalidade olimpica.

Apurou-se que ainda existem algumas lacunas que podem gerar má interpretaçăo, motivo pelo qual o texto das regras mereceu uma revisäo.

Comprovou-se que os assuntos tratados pelas Regras Internacionais de Judó não seguem uma ordem racional e que, para efeito de estudo e facilidade de entendimento, sugeriu-se a compactação dos 41 artigos em apenas sete grupos de assuntos, por apresentarem caracteristicas intimamente relacionadas

A fim de procurar transformar o Judô numa luta moderna e atraente, a Federção Internacional de Judô após acurados estudos, fez com que as regras sofressem inusitadas modificações, particularmente na década de setenta.

As denominadas novas regras de competiçāo, editdas em 1974, seriam responsáveis por um notável surto na difusão mundial desse momentoso esporte, idealizado em 1882 pelo saudoso professor Jigoro KANO.

Coube ao nosso pais, pela primeira vez, nos idos de 1974, aplicar as novas regras, por ocasião do 6 Campeonato Mundial de Judô das Forças Armadas, celebrado no Rio de Janeiro. Naquela ocasiāo, durante a Clínica Internacional de Arbitragem, organizada pela Confederação Brasileira de Judô e celebrada na Escola de Educação Física do Exército, verificou-se que as estranhas alte-

Professor Assistente da Disciplina de Judô da EEF-USP. 
raçōes eram justificáveis, a fim de que o Judô pudesse continuar figurando no elenco das modalidades olimpicas.

Sem dúvida, a demora havida na oficialização do nosso esporte como modalidade olímpica, devia-se ao fato de que a alta cúpula do esporte internacional e dos meios de comunicaçāo de massa o criticavam por sua aparente monotonia. Nos últimos anos, o sistema de arbitagem e as Regras Internacionais de Competição sofreram mais modificaçōes do que se poderia esperar, tratando-se de um esporte tão tradicional. Quem nāo acompanhou de perto as seguidas e sistemáticas modificações, atualmente, ao presenciar uma competição poderia até pensar que se estivesse tratando de uma nova modalidade esportiva de ataque e defesa.

Um dos aspectos mais importantes, foi o fato de que todos os resultados parciais (pontuações e penalidades), passaram a ser anunciados imediatamente após a realizaçāo dos lances. $O$ número de gestos realizados pelos árbitros, além de tornarem-se padronizados, foram sensivelmente aumentados, o mesmo ocorrendo com as chamadas vozes de comando.

As paralizaçōes e as interrupções da luta, deixaram de fazer parte do tempo regulamentar. A idealização da regra de nāo-combatividade e a introduçāo do placar, fizeram com que as lutas se tornassem mais dinâmicas, favorecendo o entendimento pelo público não especializado.

Todas as modificações tiveram por objetivo, também, favorecer 0 verdadeiro competidor. Aquele que lutasse mais ofensivamente levaria vantagens com as novas regras.

Depois das radicais modificações de 1974, a fim de que pudesse haver tempo hábil para que as federaçōes nacionais se inteirassem corretamente das alteraçōes e interpretaçōes havidas, progressivamente novas mudanças foram sendo implantadas, visando beneficiar realmente 0 aperfeiçoamento do Judô como esporte. Infelizmente, devido às seguidas modificaçōes, o regulamento internacional parece ter-se transformado num conjunto desordenado de artigos, além de conter repetições de recomendações. O seu texto, para ser corretamente interpretado, passou a necessitar de sistemáticas clinicas de arbitragem, não só para os árbitros mas também para os técnicos e atletas.

O objetivo desta dissertaçāo, concluída em 1981, depois de cinco anos de pesquisas, foi o de contribuir para uma melhor aprendizagem do Ju- dô como esporte de combate por estudantes de Educação Fisica, admiradores e praticantes dessa nobre arte educacional e, por que não dizer, para facilitar o entendimento do tema pelo público em geral, uma vez que o Judô, como esporte internacional, para ser admirado precisa ser compreendido não apenas por especialistas na matéria.

Em se tratando de uma trabalho didático, todas as modificações havidas, desde a sua idealizaçāo, foram comentadas e historiadas cronologicamente. Para efeito de estudo e maior velocidade de interpretação, nos permitimos sugerir que os artigos que apresentassem caracteristicas intimamente relacionadas fossem agrupados, na seguinte ordem:

\begin{tabular}{l|l}
\hline a) Grupo 1 & $\begin{array}{l}\text { Artigos de natureza geral } \\
\text { artigos que definem as funções } \\
\text { dos árbitros } \\
\text { Artigos relacionados com o julga- } \\
\text { mento de técnicas } \\
\text { c) Grupo }\end{array}$ \\
d) Grupo 4 & $\begin{array}{l}\text { Artigos sobre vozes de comando e } \\
\text { gestos } \\
\text { e) Grupos sobre infrações e penali- } \\
\text { dades } \\
\text { f) Grupo 6 } \\
\text { Artigos sobre o resultado da luta } \\
\text { Artigos que envolvem situaçōes } \\
\text { especiais }\end{array}$ \\
\hline
\end{tabular}

Ademais, todos os artigos das Regras Internacionais de Judô foram analisados tecnicamente, seguidos de recomendaçōes úteis, baseadas em fontes primárias colhidas durante anos de manifestações internacionais e em nossa experiência profissional.

Em 1984, a presente dissertaçāo foi publicada pelo Ministério da Educaçāo, através da Secretaria de Educação Física e Desportos, sob a forma de Caderno Técnico, com tiragem nacional, sendo distribuida gratuitamente em todo Território Brasileiro. As sugestōes contidas neste trabatho progressivamente estão cendo implantadas pela Federaçāo Internacional e Judô, para o contínuo aperfeiçoamento dessa apaixonante modalidade esportiva.

Como nota final, mas ao contrário em ordem de importância, registro um carinhoso agradecimento ao inesquecivel doutor Mário Nunes de Sousa, Professor Emérito da Escola de Educação Física da Universidade de São Paulo, por sua orientação segura e generosa amizade. 
Changes in the rules of competition in Judo have been historically and echnically analysed trought years, in order to study the contest rules since beginning, mainly after its transformation into international sport.

The changes were established to improve the understanding of contest by lay people, contributing for better difusion of Judo, turning the figths more dynamic and making partial and final evaluations more equitable and faster.

The sucessive changes in the Contest Rules of International Judo Federation, mainly in the seventies, were responsible for considering this sport as an ofympic modality.

It was observed that there is some lake of clarity and precision in the rules statements, resulting in false interpretations. By this reason, the rules statements were revised.

It was shown that International Judo Rules items are note in reasonable sequense and so, for studying and easying of interpretation, the classification of the 41 articles in only seven subjects groups with closely related characteristics was suggested.

\section{REFERÊNCIAS BIBLIOGRÁFICAS}

ALL JAPAN JUDO FEDERATION Contest Rules of the Kodokan Judo. Tóquio, 1951.

\section{Contest Rules}

of the Kodokan Judo. Tóquio, 1961.

\section{BRASIL. MINISTÉRIO DE EDUCAÇÃO E CUL} TURA Regras de Competição de Judó Brasilia, 1973.

BUTLER, P Judo Completo. Barcelona, Sintés, 1965.

CALLEJA, C.C. Generalidades sobre as novas regras de competição. São Paulo, Judokan do Brasil, 1974.

\section{Informaçāo so-}

bre as modificaçōes nas Regras Interna cionais de Competiçāo. São Paulo, Confederação Brasileira de Judô, 1979.

CALLEJA, C.C. \& YAMASAKI, S. Arbitragem em Judō Curso de Atualizaçāo. Sāo Paulo, Federação Paulista de Judô, 1975.

CONGRESSO TÉCNICO DO CAMPEONATO BRASILEIRO DE JUDÔ, 1 - Revista de Judô. Rio-de Janeiro, 2:18-19, 1954.

FEDERAÇÃO BRASILEIRA DE PUGILISMO. Regras que presidem os encontros de jiu-jitsu no Brasil. Rio de Janeiro, 1936.

INTERNATIONAL JUDO FEDERATION -Contest Rules of the International Judo Federation. Londres, 1979. tición de la Federación Internacional de Judo, 1974.

Reglamentos de competencia de la Federación Internacional de Judo, 1967

Regles de Compétition de la Federation Internationale de Judo 1977

Handbook of the International Judo Federation, 1974.

international judo federation. Handbook of the International Judo Federations. Berlim, 1980.

KANO, J. Judo (ju-jutsu). Tóquio, Board of Tourist Industry Japanese Governement Railways, 1937

KAWAISHI, M. Má Méthode de Judo. Paris, Judo International, 1964.

KIMURA, M. El Judo. Barcelona, Aedos, 1976.

KLINGERSTORFF H.K. Judô sem Mestre. Rio de Janeiro, Gertum Carneiro, (s.d.).

KODOKAN INSTITUTE. Judo by Kodokan. Tóquio, Nunoi Shobo, 1961.

lustré. Dai-Nippon Yubenkai Kodansha, 1955. 
LASSERRE, R. Judo. Manual Práctico. BarceIona, Hispano-Europea, 1971.

MODRIC, Z. Hey, they're trying to change Judo! Black Belt. Los Angeles, 12(6):62, 1974.

MOYSET, R. Initiation au Judo. Paris, Bonermann, 1965.

NISHIOKA, H. The Judo Referee: Shadow and Conscience of Competion. Black Belt. Los Angeles, 16(5):51-53, 1978.
ROBERT, L. Le Judo. Verviers, Gerard, 1964.

ROCHA, V.L. da Judô. Conquista de Faixas. Guanabara, Divisão de Educação Física do MEC, 1967.

ZAQUI, J. Jiu-Jitsu. Sāo Paulo, Cia. Brasil Editora, (s.d.). 